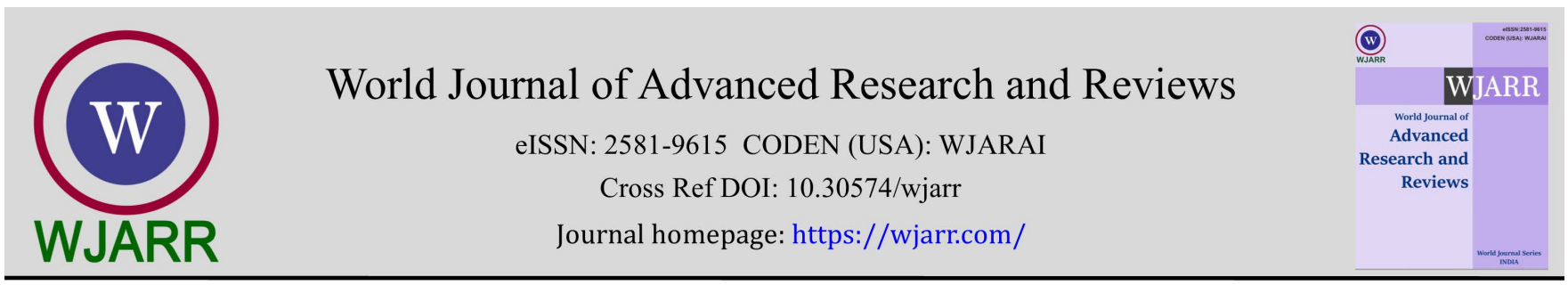

(RESEARCH ARTICLE)

\title{
Mass flow rate optimization in solar heating systems based on a flat-plate solar collector: A case study
}

\author{
Samer Yassin Alsadi ${ }^{1,}{ }^{*}$ and Tareq Foqha ${ }^{2}$ \\ Elect. Eng. Dept, Palestine Technical University-Kadoorie (PTUK), Tulkarm-Palestine.
}

World Journal of Advanced Research and Reviews, 2021, 12(03), 061-071

Publication history: Received on 25 September 2021; revised on 06 November 2021; accepted on 08 November 2021

Article DOI: https://doi.org/10.30574/wjarr.2021.12.3.0557

\begin{abstract}
Little works considered the optimization of working fluids in solar systems. Engineers, designers and scientists are interested with the optimization problems, furthermore it is very important specially, for solar systems to improve the energetic behavior and increase their efficiencies as a conversion system of solar irradiance to a useful thermal power. According to the available literature, the criteria of optimization mainly relates to energetic and economic analysis (one of them or both). The analysis was based upon the maximum useful energy obtained from solar collector. Accordingly, the optimum mass flow rate was found aspires to infinity. The second analysis is based upon minimum cost of the unit of useful energy $[\$ / \mathrm{W}]$. The optimum mass flow rate of solar air-heating flat-plate collector for the considered domestic solar heating system has been found $29 \mathrm{~kg} / \mathrm{h}$ per square meters of solar collectors. This paper deals with a third criteria that is, the amount of the additional energy required to achieve the required task from the solar system by means of auxiliary heating system. In where both the outlet temperature and mass flow rate play crucial role in the heat exchange between the fluid in the collector loop and the fluid in the load loop.
\end{abstract}

Keywords: Optimum Mass Flow Rate; Flat-Plate Solar Collector; Solar Heating System; Electrical Consumption.

\section{Introduction}

It is believed that renewable energies can substitute the conventional power plants based on fossil-fuel-fired and put an end to the global warming, as it became confirmed the role of carbon dioxide gas emitted from the chimneys of power plants in global warming and climate change [1,2], in additional many emissions that affect human health and the environment [3,4]. As a result of the electricity crisis that Palestinian cities suffer from, especially the Gaza Strip (Fig.1), where the hours of power cuts reach 18/24 hours, which prompted the government to increase in support for the use of solar collectors instead of electrical water heaters [6]. In developing countries, the residential sector occupies the largest share of the country's electrical consumption about 33\% of total consumption (Fig.1), and of domestic consumption goes to water heating in the first place (32\%) (Fig.2) [5]. The production of solar heating systems worldwide has been increasing in recent years, while production costs have been decreasing and are set to decrease further due to new manufacturing technologies and production scale factors. On the other hand, the cost of conventional energy derived from the fossil fuel sources is pressed to go up, due to the increasing penalty for environment pollution and due to the decrease of the availability of fossil fuel reserves $[6,7]$. In terms of solar collector, solar water heating flat-plate collectors represent 1,570 projects yield around $776 \mathrm{MW}, 93$ projects using concentrating solar power CSP yield $103 \mathrm{MW}$ and 104 projects using vacuum tube solar collectors yield $54 \mathrm{MW}$ th. With these experiences, Palestine leads the MENA region for total district heating capacity in operation, with more than $1 \mathrm{GW}$ at the end of 2020 [8]. Despite high penetration of solar water heaters in Palestinian, solar thermal energy represents only a small fraction of the Palestinian Energy mix (8\%) [8]. In 2019, the West Bank had 63.1\% of households having solar water heater and in the Gaza Strip was $43.8 \%$ which is providing more than $600 \mathrm{GWh}$ [8].

\footnotetext{
${ }^{*}$ Corresponding author: Samer Yassin Alsadi

Elect. Eng. Dept, Palestine Technical University-Kadoorie (PTUK), Tulkarm-Palestine.
} 


\begin{tabular}{|l|l|}
\hline$A_{c}:$ & Solar collector area, $\mathrm{m}^{2}$ \\
\hline$U_{c}:$ & Overall heat loss coefficient, $\mathrm{W} / \mathrm{m}^{2} \mathrm{~K}$ \\
\hline$Q_{c}:$ & Energy delivered out the solar collector, $\mathrm{W} / \mathrm{m}^{2}$ \\
\hline$Q_{u}:$ & Useful energy delivered out the solar system, $\mathrm{W} / \mathrm{m}^{2}$ \\
\hline$L:$ & Solar collector length, $\mathrm{m}$ \\
\hline $\mathrm{f}$ & Solar fraction \\
\hline $\mathrm{FR}:$ & Solar collector heat removal factor \\
\hline $\mathrm{FT}:$ & Solar collector working fluid heating coefficient, $\mathrm{K} / \mathrm{W}$ \\
\hline $\mathrm{Fhx}:$ & Heat exchanger penalty \\
\hline$\dot{m}_{L}:$ & Load working fluid mass flow rate, $\mathrm{kg} / \mathrm{s}$ \\
\hline$\dot{m}_{c}:$ & Solar collector working fluid mass flow rate, $\mathrm{kg} / \mathrm{s}$ \\
\hline$W_{p}:$ & Power of the pump, W \\
\hline$\Delta P:$ & Pressure drop, Pas \\
\hline $\mathrm{Re}:$ & Reynolds number \\
\hline$\rho:$ & Density, kg/m ${ }^{3}$ \\
\hline$\eta_{p u m p}:$ & Pump's efficiency \\
\hline $\mathrm{D}:$ & Inner pipe diameter, m \\
\hline
\end{tabular}

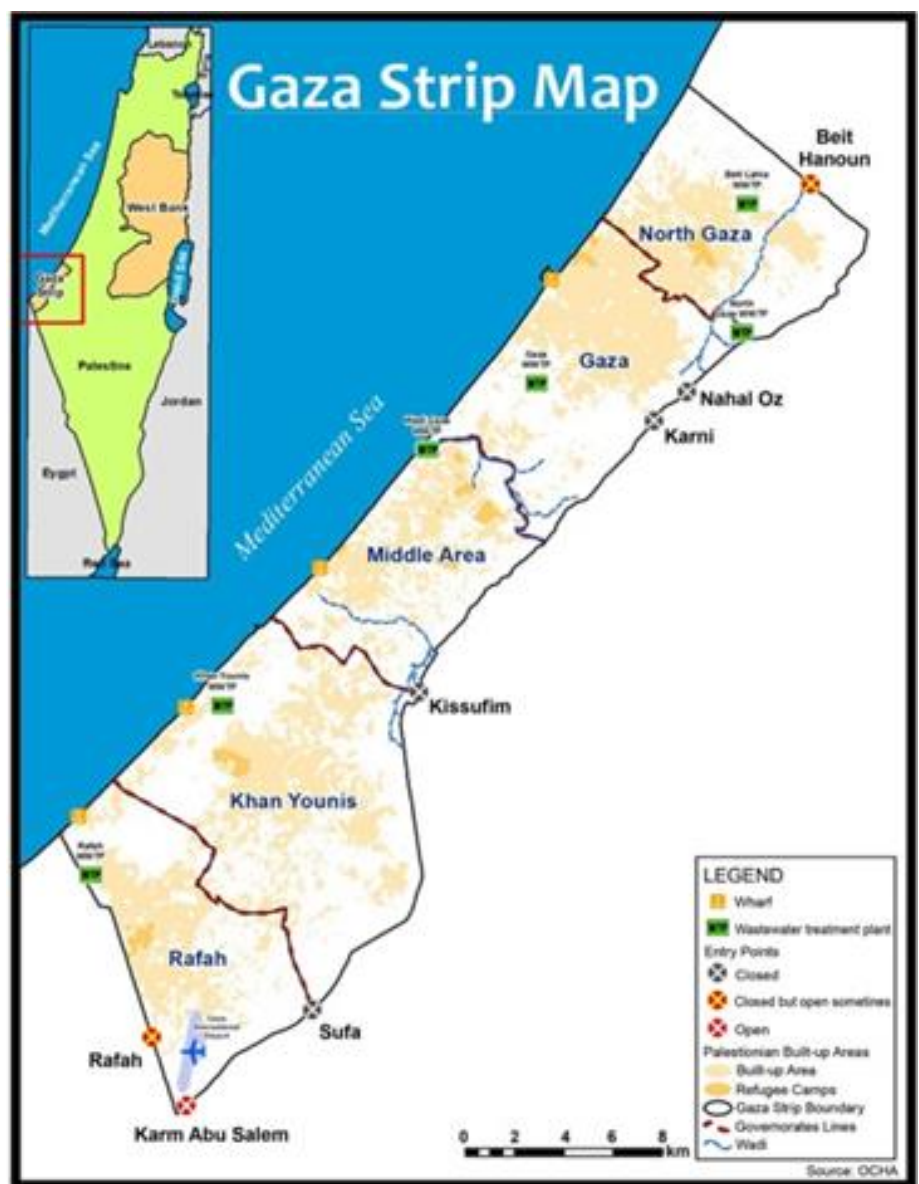

[source: https://ar.m.wikipedia.org/wiki/\%D9\%85\%D9\%84\%D9\%81:Gaza_Strip_map2.svg]

Figure 1 Gaza Strip map 
The search for new alternatives to produce pollution-free energy is nowadays included in government planning worldwide. Solar energy, in this context, can be considered as a true competitive alternative for the near future. Recently Palestine has shown interest in fully developing renewable energy, especially wind and solar energies which is known to have high potential [9-12]. Sensibility analysis is useful in order to evaluate the effect of design parameter variation, as well as the operating parameters such as the mass flow rates through the solar system components, leading to maximum economic effect and reliability $[13,14]$

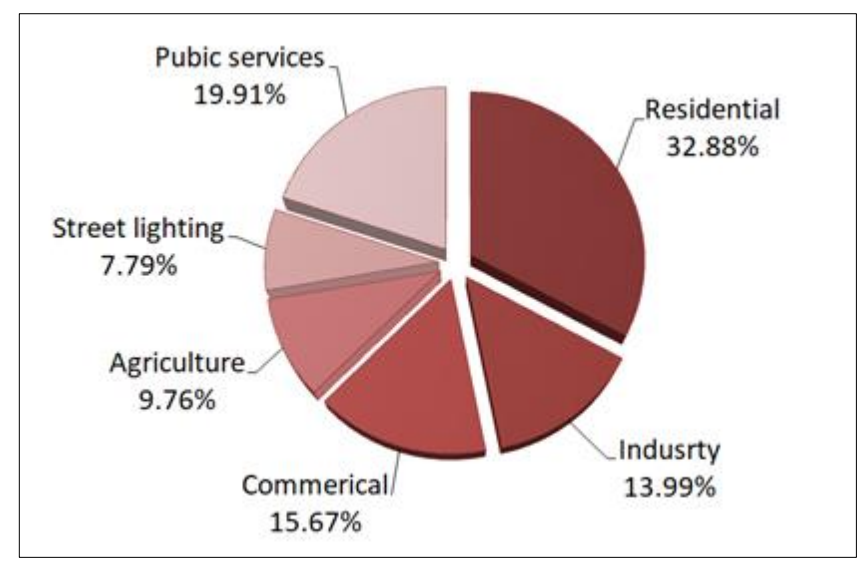

Figure 2 Distribution of electricity load in Palestine

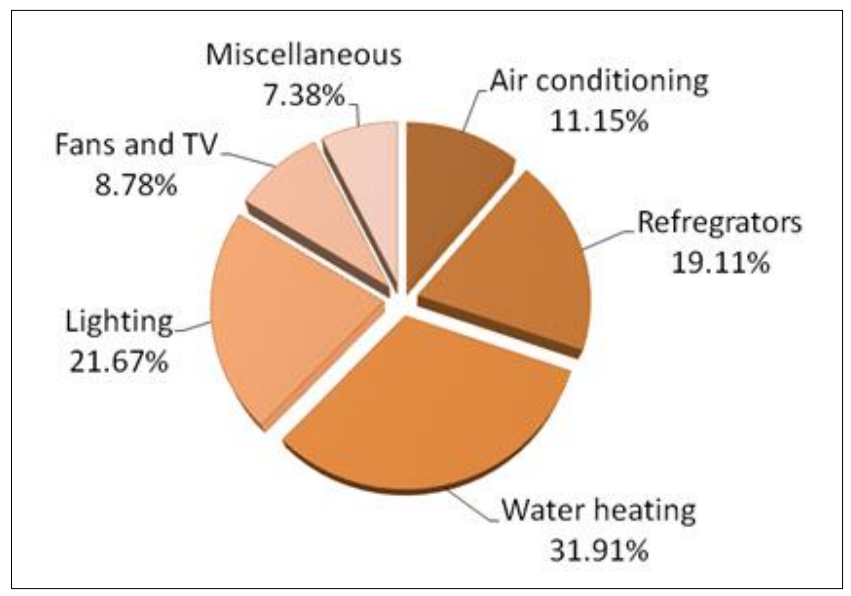

Figure 3 Distribution of housing sector load

Many authors considered the PV solar fields [15-28], however, thermal solar collectors have remained far from scientific research despite their impor8ance in covering a significant portion of the electrical loads.

Early Beckman, Klein and Duffie [29] attempted to get the optimum working fluid mass flow rate through the collector according to the maximum solar collector efficiency. The authors believe that, the solar collector never works alone and almost engaged with other components such as heat exchanger, distribution system, thermal storage, auxiliary system, etc. and the optimization must be taken to all system. Furthermore, the criteria of optimization must be more comprehensive such as economic, energetic and environment effects. Later Nassasr [30] has presented a methodology to optimize the mass flow rate in a solar heating system provides the necessary power for hot water supply and space heating to a house locates in Gaza-Palestine, the economic effect was adopted as a criteria for optimization.

\section{Methodology}

The approach followed to achieve the objectives of this research is depicted by the flowchart shown in Fig. 4 . 


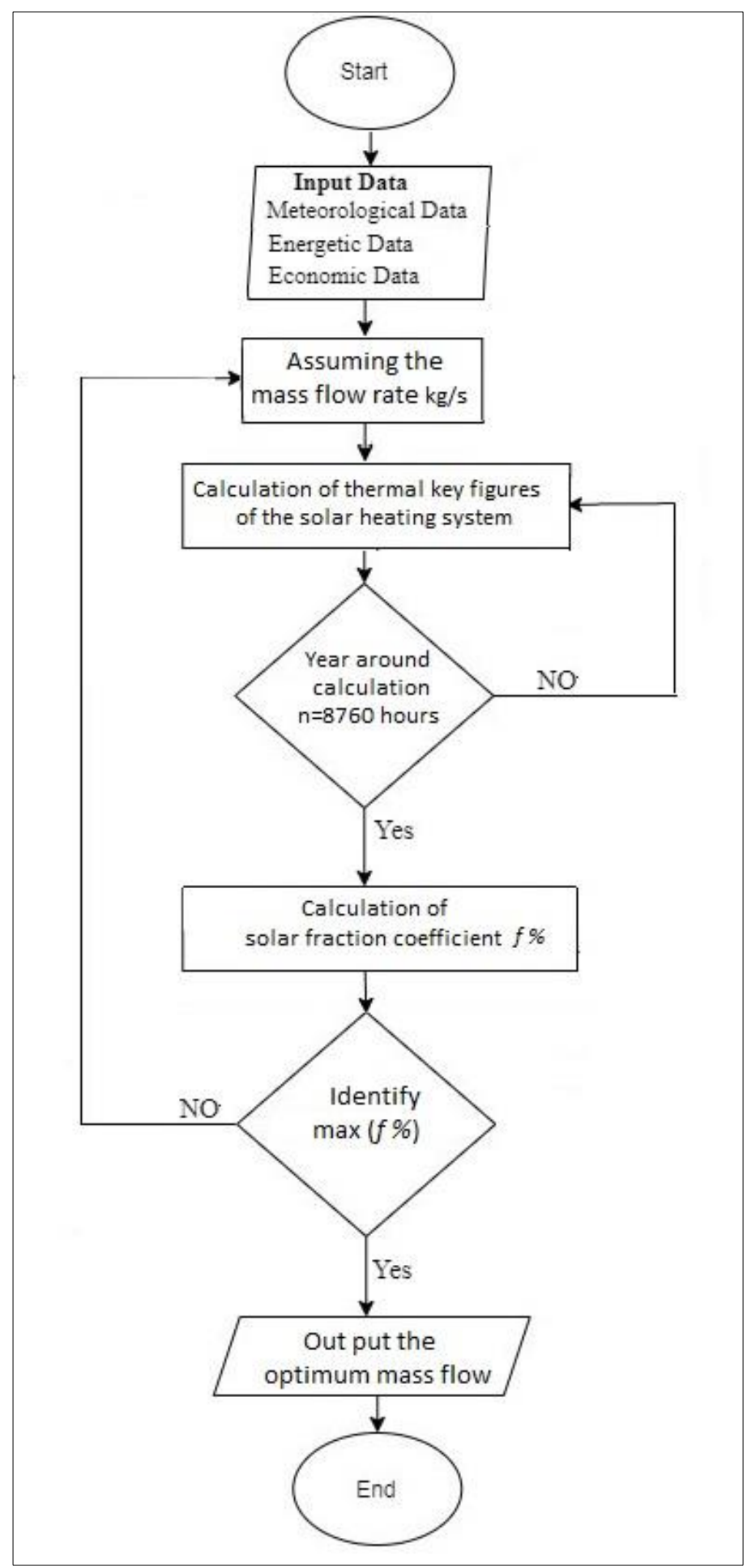

Figure 4 The flowchart of proposed optimization procedure for the mass flow rate of a solar heating system

\subsection{Solar radiation}

It is better to obtain time series measured solar radiation data from meteorological stations, but in the absence of it, there are two other options: obtaining it from databases or by calculating it using mathematical models [31-33]. In this research the first option has been chosen. The tilt angle $(\beta)$ of the solar collectors are mounted as $27^{\circ}$ south facing as recommended by $[34,35]$. In order to estimate the global tilted solar radiation $\left(H_{t}\right)$ the following eqn is used $[31,32]$ :

$$
H_{t}=H_{b} R_{b}+H_{d} R_{d}+H_{g} R_{r}
$$


Where: $H_{g}, H_{b}, H_{d}$ are global, beam and diffuse horizontal solar irradiance in $\left(\mathrm{W} / \mathrm{m}^{2}\right)$.

The transposition factor $\left(R_{b}\right)$ is represented as a function of Sun's location in the sky and the geometrical parameters of the tilted surface by [31, 32],

$$
R_{b}=\max \left(0, \frac{\cos \theta_{i}}{\cos \theta_{z}}\right)
$$

Where $\theta_{i}, \theta_{z}$ are solar angle of incidence and zenith angle respectively? Similarly, $R_{r}$ is the transposition factor for ground-reflected solar irradiance and it is given by [31, 32]:

$$
R_{r}=\rho_{g} \frac{1-\cos \beta}{2}
$$

Where $\rho_{g}$ is ground-albedo? The value of $\rho_{g}$ is a positive value less than one according to the reflectivity of the ground surrounding the collector. $\rho_{g}$ is usually assumed a constant 0.2 [36]. However, some transposition models as Sandia use variable value for $\rho_{g}[36]$.

While the sky diffuse transposition factor $\left(R_{d}\right)$ is chosen according to Nassar et. al, recommendation [37], they recommended to use HDKR model for Gaza Strip's cities. Consequently Rd will be stated as:

$$
R_{d}=F_{\text {Hay }} R_{b}+\left(1-F_{\text {Hay }}\right)\left(\frac{1+\cos \beta}{2}\right)\left[1+f \sin ^{3}\left(\frac{\beta}{2}\right)\right]
$$

Where: $F_{H a y}=\left(\frac{H_{b h}}{H_{e x t}}\right)$ is Hay's sky-clear factor, $I_{b h}$ is the horizontal beam solar irradiance, $I_{\text {ext }}$ is the extraterrestrial solar irradiance, and $f=\sqrt{\frac{H_{b}}{H_{g}}}$

Simulation is a prerequisite step for design as well as the optimization of the solar system parameters. It helps in predicting the effect of changing upon the required solar system components volume needed for achieve a certain task. Optimization of any solar system should use the dynamic simulation of the solar collector as well as other components. In any system simulation problem, mathematical modeling of all components should be done and an algorithm for the solution should be designed to facilitate computation in computers. The simulation of the collector has already been established and developed by a lot of scientists and is well presented in many solar energy textbooks [31,32], and papers, such as [38]. This paper deals with four designs of domestic solar heating systems as following:

- Solar heating system based on an air type flat-plate solar collector for space heating (no heat exchanger). Solar heating system based on an air type flat-plate solar collector for hot-water supply and/or space heating (with heat exchanger).

- Solar heating system based on a liquid type flat-plate solar collector for hot-water supply and/or space heating (no heat exchanger).

- Solar heating system based on a liquid type flat-plate solar collector for hot-water supply and/or space heating (with heat exchanger)

- Solar heating system based on an air type flat-plate solar collector for hot-water supply and space heating involving a heat exchanger and liquid type thermal storage tank .

Furthermore, the solar system consists of the energy distribution and pumping system and an auxiliary energy system should participate in any solar system to meet the required load demand. Figure I schematically presents the above listed solar system components, where Fig 5-a presents the systems listed above by I and 3 and Fig. 5-b presents the systems listed above by 2 and 4 . 


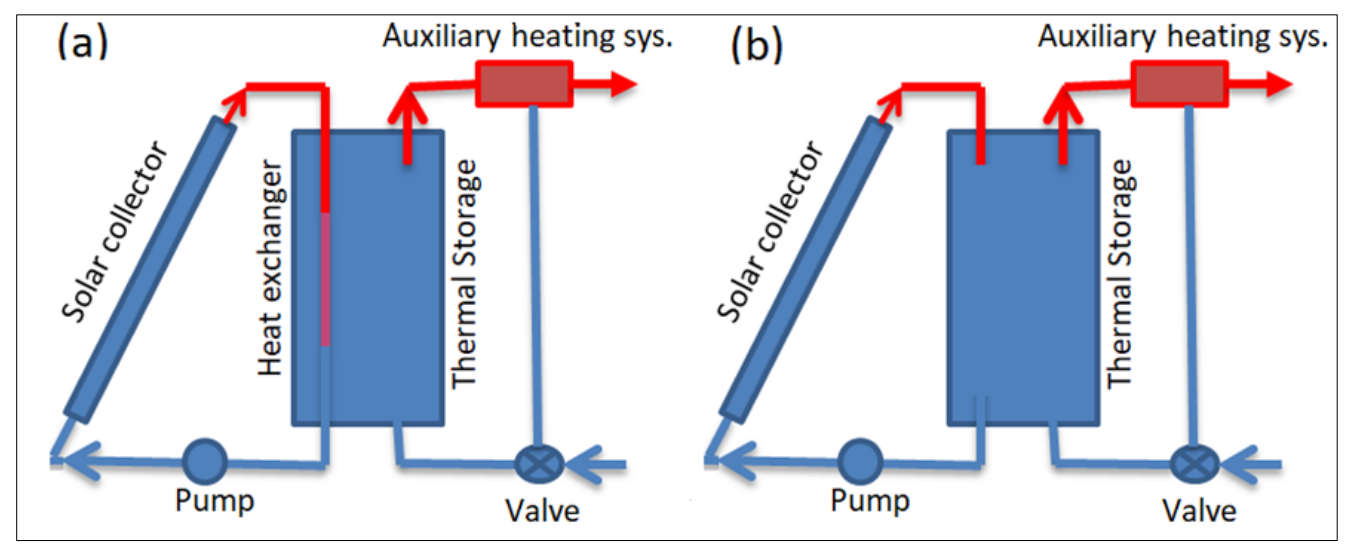

Figure 5 Schematic diagram of several arrangement of solar heating system, with HE (a) and without HE (b)

\subsection{Mass flow rate influence on the solar system characteristics}

\subsubsection{Thermal behavior of solar collector}

Mainly there are four coefficients which determine the thermal behavior of solar collectors, those are: the overall heat loss coefficient $\boldsymbol{U} \boldsymbol{c}$, the efficiency factor $\boldsymbol{f}^{\prime}$, the heat removal factor $\boldsymbol{F} \boldsymbol{R}$ and the collector efficiency $\boldsymbol{\eta}$. The working fluid mass flow rate through the collector is directly proportional with the desirable values of these coefficients, that means, the increasing in mass flow rate leads to decreasing the overall heat loss coefficient, increasing the efficiency factor, heat removal factor and the thermal efficiency of the solar collector. From this point of view, Beckman, Klein and Duffie indicated in [29] found that, the optimum mass flow rate of the working fluid aspires to infinity. On the other hand this procedure will decrease the outlet fluid temperature from the solar collector. Nassar [30] has developed a new coefficient called "working fluid heating factor $\boldsymbol{F T}$ ", this factor is similar to the heat removal factor, but it determines the degree of heating at a given mass flow rate, and it is given by:

$$
F T=\frac{F R}{\dot{m} C p}
$$

Where: $\dot{m}$ is the mass flow rate in $\mathrm{kg} / \mathrm{sec}$, and $C p$ is the specific heat capacity in $J / \mathrm{kg} / \mathrm{K}$

Accordingly, the temperature difference $\Delta T_{f}$ between the inlet and outlet of the working fluid through the collector will be found by:

$$
\Delta T_{f}=F T A_{c}\left(H_{t}(\tau \alpha)-U_{c}\left(T_{f i \tau \alpha}-T_{\infty}\right)\right)
$$

Where: $(\tau \alpha)$ stated for the optical efficiency of the solar collector, $U_{c}$ presented the overall heat loss coefficient in $W / m^{2} K, T_{\text {fica }}$ and $T_{\infty}$ are indicated for the inlet fluid temperature and the ambient temperature in ${ }^{\circ} \mathrm{C}$, respectively.

The analysis of influence of the mass flow rate on working fluid heating factor $F T$ is submitted depending on the heat removal factor $F R$. It is clear that, the increase of the mass flow rate results to decrease the working fluid heating factor. Noting that, it's impossible to optimize the parameters of the solar collector separately without considering the climatic and load characteristics.

\subsubsection{Design and operating condition}

The design condition is the size of the components of the solar system, i.e. the piping and pumping system, thermal storage device, the auxiliary system and the heat exchanger (in systems 2,4 ). The main operating condition is the working fluid mass flow rate per unit area of the collector $\dot{m} / A_{c}$. The mass flow rate is very critical if small tube diameters are used. The analysis of Nassar [30] showed that the value of $0.01 \mathrm{~kg} / \mathrm{m}^{2} s$ is a suitable for small tube diameters only and higher values can be used for inner diameters that are larger than $0.008 \mathrm{~m}$. The increase of mass flow rate leads to increase the size of the solar elements. Diameter of the pipes for gas or liquid type solar system will be chosen according to ASHRAE [39] recommendations depending on the velocity of the flow to avoid noise. As well known, there is a decisive factor for pump selection but it has also an effect on the performance of the solar energy 
system to which the collector is coupled. The power of the pump per unit area of collector $W_{p}$ may be calculated from [32].

$$
\begin{gathered}
W_{p}=\frac{\Delta P \dot{m}}{\rho \eta_{\text {pump }}} \\
\Delta P=\frac{1}{2}\left[\left(K_{\text {in }}+K_{\text {out }}\right)+f \frac{L}{D}\right] \rho v^{2} \\
f=\left\{\begin{array}{c}
\frac{64}{R e} \operatorname{Re} \leq 2,300 \\
0.316 \operatorname{Re} \frac{\operatorname{Re} 25}{R e}>2300 \\
v=\frac{\dot{m} A_{c}}{\frac{\pi}{4} \rho N D^{2}}
\end{array}\right.
\end{gathered}
$$

Where: $\rho$ is the density of the working fluid $\mathrm{kg} / \mathrm{m}^{3}, \eta_{\text {pump }}$ is the pump efficiency and $R e$ is the Reynolds number, $K_{\text {in }}$ and $K_{\text {out }}$ are inlet and outlet loss coefficients having values of 0.64 and 1.5 , respectively.

DeWinter [39] has developed a closed-form expression for the energy delivery penalty resultant from the use of heat exchanger Fhx , the analytical expression for Fhx was found as:

$$
F h x=\frac{1}{\left.1+\left\lceil\frac{F R U_{c} A_{c}}{(\dot{m} C p)_{c}}\right\rceil \frac{(\dot{m} C p)_{c}}{(\dot{m} C p)_{\min } \varepsilon_{h x}}-1\right]}
$$

Where: $\varepsilon_{h x}$ is the effectiveness of heat exchanger?

The useful energy delivered out the heat exchanger will be as [38]:

$$
Q_{u}=F h x A_{c} Q_{c}
$$

Of course the size of the thermal storage will be increased to store the additional quantity of working fluid mass flow rate. An increase in storage size does not appreciably decrease the auxiliary heat share [41]. Furthermore, this procedure will increase the energy losses out the storage and increase the capital cost of the system.

\subsubsection{Objective function of optimization}

The objective function of optimization can be a performance criterion or a cost criterion. The cost criterion should also include the performance of the collector measured by the useful heat and the fluid outlet temperature. Both these values affect the performance of any solar energy system. For example, consider a plant composed of a collector and a Rankine cycle power loop. An increase in the liquid mass flow rate increases the collector efficiency, but decreases the outlet temperature and, hence, decreases the thermal efficiency of the Rankine cycle. Also, the pumping power in the collector loop increases upon increasing the liquid mass flow rate. In this case, the mass flow rate of the working fluid in the collector should be chosen such that the overall output from the plant is the maximum. A reasonable choice of the objective function for a solar heating system might be the fraction factor, which represents the ratio of the total load covered by the solar system to the total demand load, or in other words the objective function might be the amount of additional energy by means of auxiliary system to meet the total load needing. 


\section{Results and discussion}

A computer program has been written in order to simulate the thermal behavior of solar systems with different arrangements and components. Constant load characteristics were adopted and the desirable load temperature was 60 ${ }^{\circ} \mathrm{C}$. The additional energy $Q_{a d d}$ applied via auxiliary heating system will be equal to:

$$
Q_{a d d}=\dot{m}_{L} C p A_{c}\left(60-T_{s}\right)^{+}
$$

Where: $T_{s}$ stated for thermal storage temperature in ${ }^{\circ} \mathrm{C}$

The superscript (+) appears in eqn. (10) means that only positive quantity will be considered otherwise the value will be equal to zero.

The fraction factor $(f)$ is considered as an energetic and economic indicator of the system. It can be easily obtained hence the useful energy delivered by the solar system and the additional energy supplied via the auxiliary heating system, and written as:

$$
f=\left[1+\frac{Q_{a d d}}{Q_{u}}\right]^{-1}
$$

The results were obtained and plotted in Figs 6, 7 and 8, show that the optimum energetic behavior of the solar system occurs when the heat capacities of the two masses in the collector loop and in the load loop are equals.

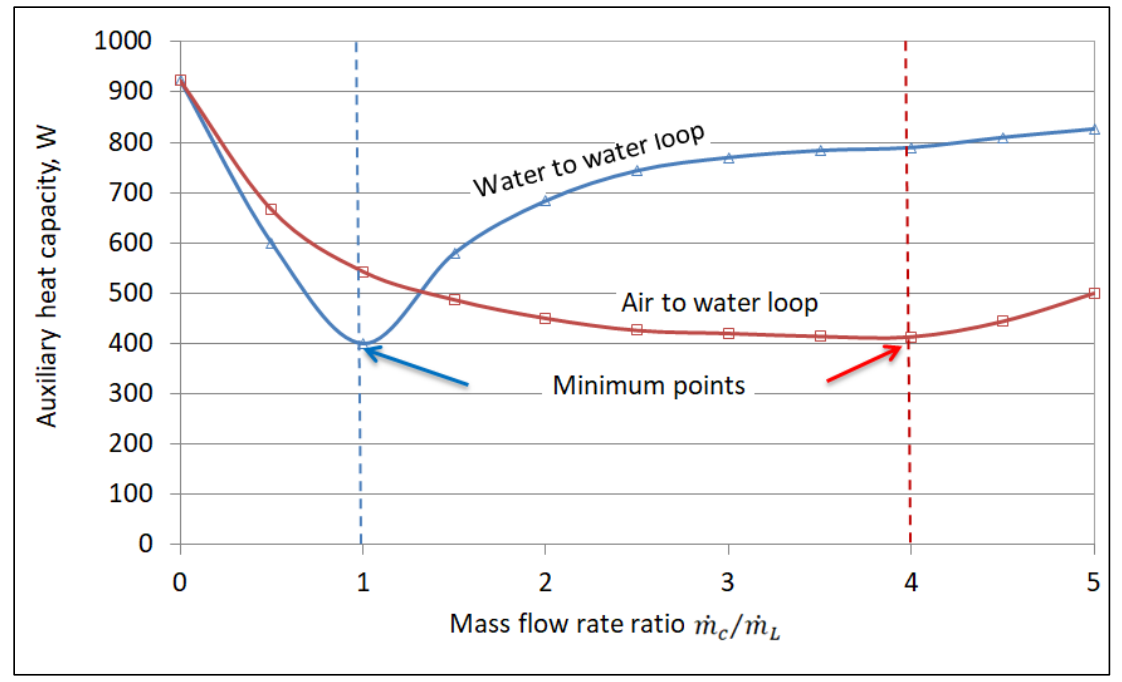

Figure 6 Relation between the auxiliary heat capacity and the mass flow rates ratio of the working fluid in the collector $\left(\dot{\boldsymbol{m}}_{\boldsymbol{c}}\right)$ to the load mass flow rate $\left(\dot{\boldsymbol{m}}_{\boldsymbol{L}}\right)$ for the solar system (a)

It is clear from Fig. 6 that the optimum mass flow rate ratio is located at the point when the heat capacity of the working fluids is equals. Air to air flow the heat capacity ration is equal to one so that the optimum mass flow rate ratio is also equals to one, while in the case of air to water flow the ration is four so the air mass must be four times the water mass to achieve the optimum behavior the system is the same. In the situation the mass flow rate of each loop is the same. In fact, this result supports what was presented above in Fig. 6, because the heat capacity ratio in the case of similar fluids flow in both loops is one, therefore, the fluid flow ration is also equal to one for both sides.

Fig.7 illustrated the thermal characteristics of a solar system without heat exchanger, so the working fluid flows through.

It is evidence from Fig. 8 that the maximum solar fraction factor is obtained when the mass flow rate equals the unity. 


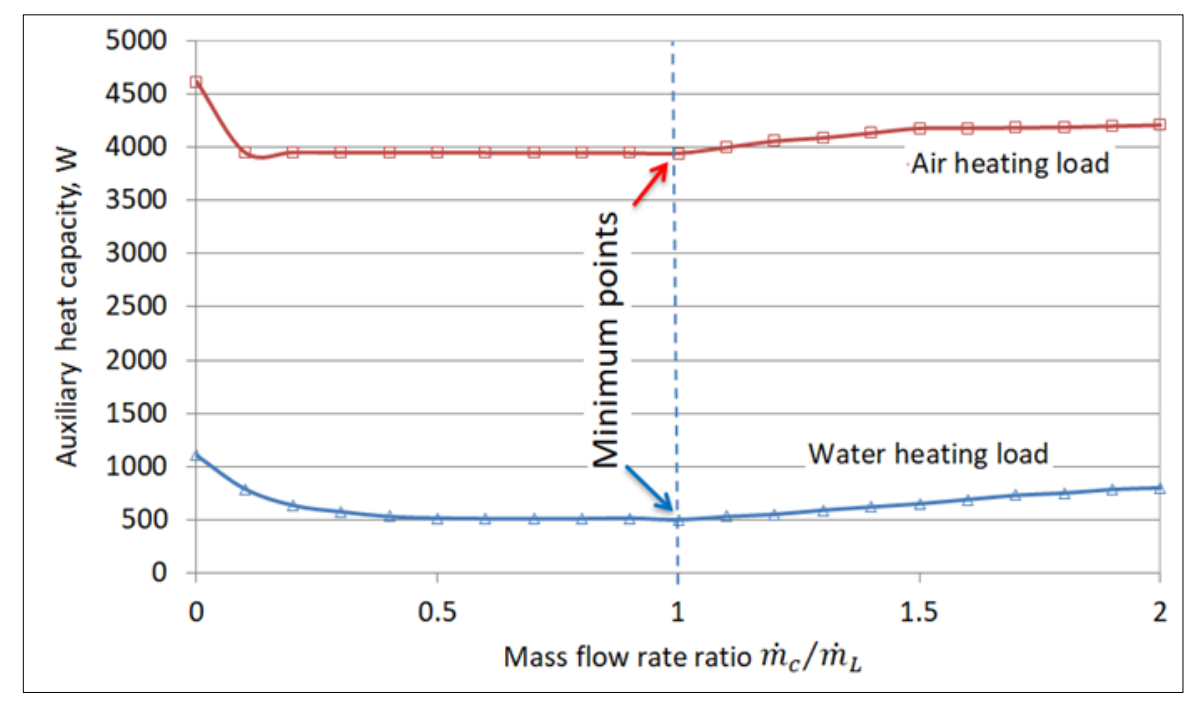

Figure 7 Relation between the auxiliary heat capacity and the mass flow rates ratio of the working fluid in the collector $\left(\dot{\boldsymbol{m}}_{c}\right)$ to the load mass flow rate $\left(\dot{\boldsymbol{m}}_{\boldsymbol{L}}\right)$ for the solar system (b)

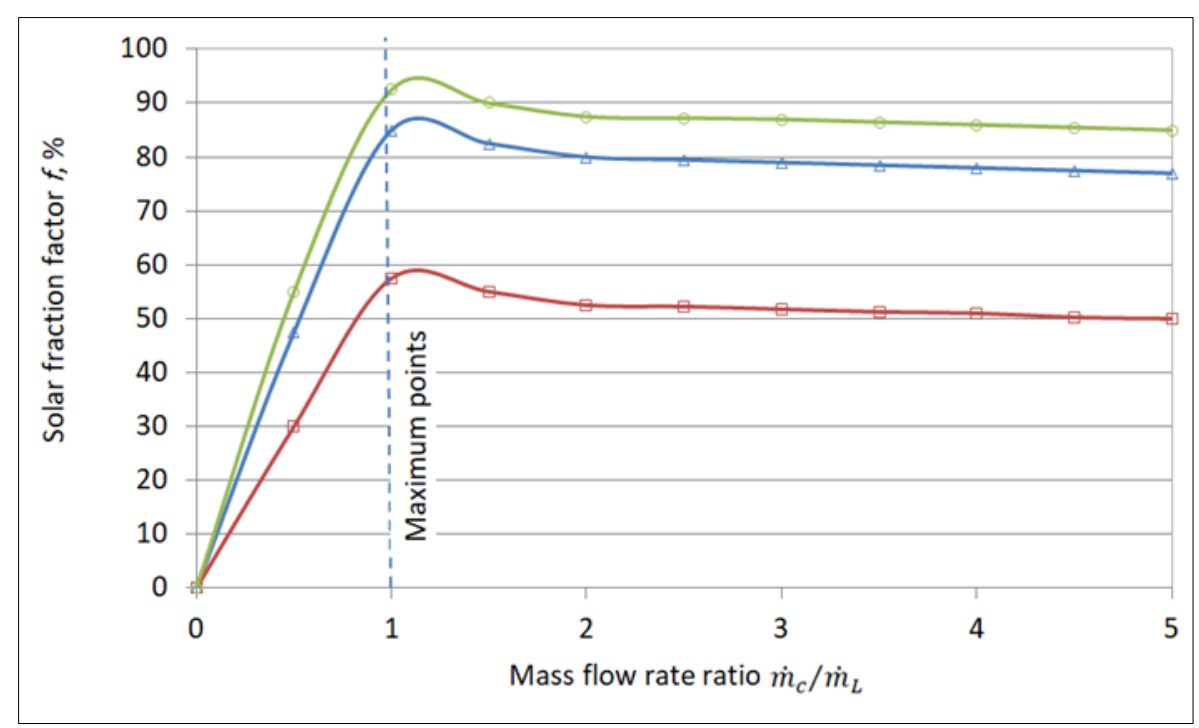

Figure 8 Relation between the solar system fraction factor and the mass flow rates ratio of the working fluid in the collector $\left(\dot{\boldsymbol{m}}_{\boldsymbol{c}}\right)$ to the load mass flow rate $\left(\dot{\boldsymbol{m}}_{L}\right)$.

\section{Conclusion}

The obtained results were deferent those obtained by Beckman, Klein and Duffie and Nassar, because the criteria of optimization are deferent. However this study showed that the optimum mass flow ration is equal to the ratio of heat capacities of the working fluids in collector - thermal storage and the termal storage - load loops.

\section{Recommendations}

According to the results of the present study, the authors would like to advice the following recommendations:

- The optimization procedure must be taken for all the system.

- Study of any system must be considered the economic, environment and social effect of utilize such systems.

- Study the influence of the unsteady load mass flow rate on the solar system behavior. 


\section{Compliance with ethical standards}

\section{Acknowledgments}

The researchers would like to thank Palestine Technical University- Kadoorie (PTUK) for continuous support the applied research.

\section{Disclosure of conflict of interest}

The authors hereby declare there is no conflict of interest.

\section{References}

[1] Nassar Y, Aissa K, Alsadi S. Air Pollution Sources in Libya. Research \& Reviews: Journal of Ecology and Environmental Sciences. 2017; 5: 63-79.

[2] Nassar Y, Salem M, Iessa K, AlShareef I, Amer K, Fakher M. Estimation of CO2 emission factor for the energy industry sector in libya: a case study. Env. Dev. Sustain. 2021.

[3] Nassar Y, Aissa K, Alsadi S. Estimation of Environmental Damage Costs from CO2e Emissions in Libya and the Revenue from Carbon Tax Implementation. Low Carbon Economy. 2017; 8: 118-132.

[4] S Yousif, A Salem, Y Nassar, I Bader. Investigation of pollutants dispersion from power stations ,International journal of energy research. 2006; 30(15): 1352-1362.

[5] Nassar Y, Alsadi S. Economic and environmental feasibility of the renewable energy as a sustainable solution for the electricity crisis in the Gaza Strip, International Journal of Engineering Research and Development. 2016; 12 (3): 35-44.

[6] Nassar Y, Amer K, Irhouma, M, Ahmad S. Economic and environmental assessment of electrical generators: A case study of southern region of Libya, International Journal of Energy Policy and Management. 2015; 1(4): 64-7.

[7] Hafez A, Nassar Y, Hammdan M, Alsadi S. Technical and Economic Feasibility of Utility-Scale Solar Energy Conversion Systems in Saudi Arabia, Iranian Journal of Science and Technology, Transactions of Electrical Engineering, Transactions of Electrical Engineering. 2019.

[8] World Bank, "West Bank \& Gaza energy efficiency action plan 2020-2030, Final report," The World Bank. 2018.

[9] Asadi SY, Nassar YF. A Numerical Simulation of a Stationary Solar Field Augmented by Plane Reflectors: Optimum Design Parameters, Smart Grid and Renewable Energy. 2017; 8(7), 221-239.

[10] Nassar Y, Alsadi S. Assessment of solar energy potential in Gaza Strip-Palestine ,Sustainable Energy Technologies and Assessments. 2019; 31: 318-328.

[11] Nassar Y, Alsadi S. Wind energy potential in Gaza Strip-Palestine state, Solar Energy and Sustainable Development. 2018; 7(2): 41-57.

[12] Amer K, Fakher M, Ahmad S, Irhouma M, Altahbao S, Salem E. Performance of domestic solar heating system with thermal storage using phase change materials. International Journal of Engineering Research and Development. 2020; 16(9): 01-11.

[13] Nassar Y. Thermodynamics analysis and optimization procedure for domestic solar water heating system, AASCIT, American Journal of Energy and Power Engineering. 2015; 2(6): 92-99.

[14] Nassar Y, Salem A. Solar energy \& energy conservation in buildings, 1st International Congress of MechanicsConstantine Faculty of Engineering Department of Mechanical Engineering, University of Constantine, Algeria. 14-16 December 2002

[15] Alsadi S, Nassar Y. A general expression for the shadow geometry for fixed mode horizontal, step-like structure and inclined solar fields, Solar Energy. 2019 181: 53-69.

[16] Awad H, Nassar Y, Hafez A, Sherbiny M, Ali A. Optimal design and economic feasibility of rooftop photovoltaic energy system for Assuit University, Egypt, Ain Shams Engineering Journal. 2021.

[17] Ali A, Karram E, Nassar Y, Hafez A. Reliable and economic isolated renewable hybrid power system with pumped hydropower storage, 22th international Middle East power systems conference (MEPCON 2021), Assiut University, Assiut-Egypt. 2021. 
[18] Nassar Y. Simulation of solar tracking systems, Energy \& Life Journal. 2005; 21: $81-90$.

[19] Nassar Y. Analytical-numerical computation of view factor for several arrangements of two rectangular surfaces with non-common edge, International Journal of Heat and Mass Transfer. 2020; 159.

[20] Nassar Y, Alsadi S. View factors of flat solar collectors array in flat, inclined, and step-like solar fields. J. Solar Energy Eng. ASME Trans. 2016; 138: 1-8.

[21] Nassar Y, Alsadi S, Amer K, Yousef A, Fakher M. Numerical Analysis and Optimization of Area Contribution of The PV Cells in the PV/T Flat-Plate Solar Air Heating Collector, Solar Energy Research. 2019.

[22] Nassar Y, ElNoaman A, Abutaima A, Yousif S, Salem A. Evaluation of the underground soil thermal storage properties in Libya, Renewable energy. 2006; 31(5, pp. 593-598.

[23] Nassar Y, Hadi H, Salem A,. Time Tracking of the Shadow in the Solar Fields, J. Sebha Univ. 2008; 7(2): 59-73.

[24] Nassar Y, Hafez A, Alsadi S. Multi-factorial comparison for 24 distinct transposition models for inclined surface solar irradiance computation in the state of Palestine: a case study. Front. Energy Res. 2020; 7: 163.

[25] Nassar Y, Salem A. The reliability of the photovoltaic utilization in southern cities of Libya, Desalination. 2007; 209: 86-90.

[26] Nassar Y, Salem A, Sergievsky E. A creation of mathematical model for photovoltaic/thermal (PV/T) solar flatplate collector, International conference on renewable energy for regional development CIGA, Bogor - Indonesia. $2001 ; 28-31$.

[27] Nassar Y, Yousif S, Salem A. The second generation of solar desalination systems, Desalination. 2007; 209: 177181.

[28] Salem A, Nassar Y, Yousif S. The Choice of Solar Energy in the Field of Electrical Generation-Photovoltaic or Solar Thermal - For Arabic Region, World Renewable Energy Congress VIII (WREC 2004). 2004.

[29] Beckman, Klein and Duffie, Calculation of solar heating systems. 1982.

[30] Nassar Y.F, Development of solar heating systems, Ph.D. thesis, Moscow Power Engineering Institute (Technical University), Moscow, 1999.(in Russian language).

[31] Duffie JA, Beckman WA. Solar engineering of thermal processes, John and Wiley, NewYourk, 14th ed. 2013.

[32] Nassar Y. Solar energy engineering active applications, Sabha University, Libya. 2006.

[33] Alsadi SY, Nassar YF. Correction of the ASHRAE Clear-Sky Model Parameters Based on Solar Radiation Measurements in the Arabic Countries. International Journal of Renewable Energy Technology Research. 2016; 5: 1-16.

[34] Alsadi S, Nassar N. General polynomial for optimizing the tilt angle of flat solar energy harvesters based on ASHRAE clear-sky model in mid and high latitudes, Energy and Power. 2016; 6(2).

[35] Alsadi S, Nassar Y. Energy demand based procedure for tilt angy, le optimization of solar collectors in developing countries, Journal of Fundamentals of Renewable Energy and Applications. 2017; 7: 225.

[36] Alsadi S, Nassar Y. Estimation of Solar Irradiance on Solar Fields: An Analytical Approach and Experimental Results. IEEE Transactions on Sustainable Energy. 2017; 8(4): 1601-1608.

[37] Nassar Y, Hafez A, Alsadi S. Multi-Factorial Comparison for 24 Distinct Transposition models for Inclined Surface Solar Irradiance Computation in the State of Palestine: A Case Study. Front. Energy Res. 2020; 7: 163.

[38] Nassar YF, Sergievsky ED. Heat transfer in flat-plate solar air-heating collectors, Sixth international conference on advanced computational methods in heat transfer, Heat Transfer 2000, Madrid, June 2000; 575-584.

[39] ASHRAE hand book of fundamentals, Atlanta. 1989.

[40] DeWinter F. Heat exchanger penalties in double loop solar water heating systems, solar energy. 1975; 17 335337.

[41] Nassar Y, Salem A. The utilization concept of the thermal storage in solar heating systems, International forum on renewable energies -FIRE 2002, Tetuan, Morocco. 2002; 389-394. 